\title{
Monographs Editors
}

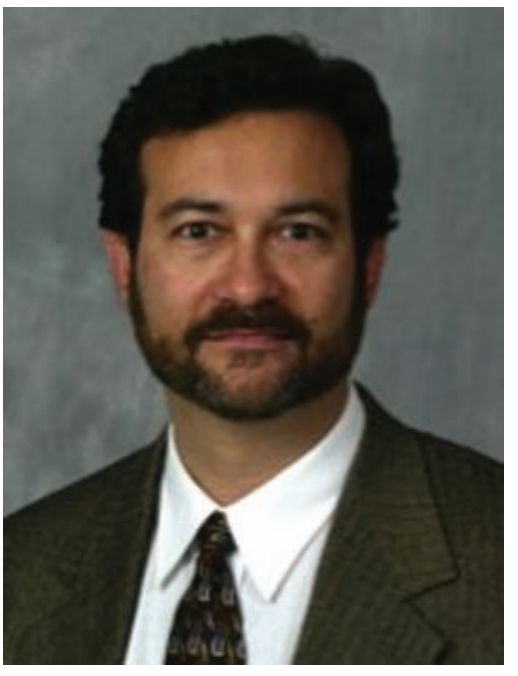

\section{Irwin H. Gelman}

Irwin Gelman has focused on characterizing the role of Src-family and FAK tyrosine kinases in regulating signaling and cytoskeletal pathways that govern metastatic behavior such as invasiveness, survival, and neovascularization. The Gelman lab helped define the role of SSeCKS/Gravin/AKAP12, which encodes a kinase scaffolding protein that is downregulated by oncogenic Src and Ras, in metastasis suppression and mitogenic control in prostate cancer. They have also studied the role of Src-family and Ack1 kinase tyrosine phosphorylation of the androgen receptor in the progression to castration-resistant disease. This has led to collaboration with biotechnology companies such as Kinex Pharmaceuticals, LLC, to identify novel small molecule inhibitors of SFK as therapeutics against recurrent and metastatic cancer. The Gelman lab has now begun to identify novel FAK substrates involved in cancer progression using proteomic screens, and to identify novel metastasis-regulating genes using genomic shRNA screens.

Born in New Haven, Connecticut, Dr. Gelman began his research interests during high school in a hematology research lab at Yale Medical School. He received his BA (high honors) in biochemistry from Wesleyan University, followed by MA, MPh, and $\mathrm{PhD}$ degrees in microbiology from Columbia University, where he worked with Saul Silverstein to map herpes simplex virus regulatory circuits. He was an American Cancer Society Postdoctoral Associate in the lab of Hidesaburo Hanafusa at The Rockefeller University, studying mechanisms of Src-induced oncogenesis, and then joined the faculty of the Departments of Microbiology and Infectious Diseases (Medicine) at Mount Sinai School of Medicine in 1990. In 2003, he moved to the Roswell Park Cancer Institute, where he is now the John and Santa Palisano Chair of Cancer Genetics, professor of oncology, and chair of the Cell and Molecular Biology Program at the State University of New York at Buffalo, co-leader of the Molecular Epidemiology and Functional Genetics Program of the Roswell Park Comprehensive Cancer Center, and director of the Advanced Cancer Genomics Program at Roswell Park Cancer Institute. He has served on multiple NIH and DOD grant and programmatic study sections, and on the National Functional Genomics Center advisory board.

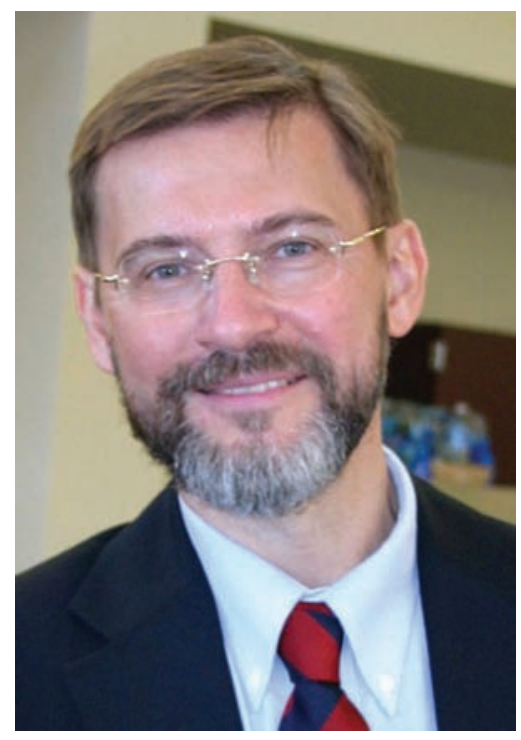

\section{Marius Sudol}

Dr. Marius Sudol is a staff scientist at the Weis Center for Research in Pennsylvania and an adjunct faculty member at the Department of Medicine of Mount Sinai School of Medicine in New York City. Dr. Sudol was instrumental in the delineation and characterization of one of the smallest protein-protein interaction modules, the WW domain. His work also implicated the WW domain in signaling pathways underlying several human diseases, including Liddle syndrome of hypertension, Golabi syndrome of mental retardation, and cancer. He earned a PhD at The Rockefeller University in New York in 1983 and stayed at his alma mater as a postdoctoral fellow and faculty member until his move to Mount Sinai in 1995. Dr. Sudol has published 110 research articles and has also participated in the generation of the first protein interaction map for the human modular protein domain. His current work focuses on the details of signaling mechanisms that use the WW domain complexes and underlie human diseases. In particular, his laboratory studies the Hippo tumor suppressor pathway, which is regulated by a network of multiple WW domain complexes. 